\title{
Importance of Müller Cells
}

\author{
Sabiha Gungor Kobat, ${ }^{1}$ () Burak Turgut ${ }^{2}$ \\ 'Department of Ophthalmology, Health Science University, Elazıg, Turkey \\ ${ }^{2}$ Department of Ophthalmology, On Sekiz Mart Unıversity, Canakkale, Turkey
}

\begin{abstract}
Müller cells (MCs) are the most common glial cell found in the human retina. MCs have an important role in architectural and metabolic functions in the retina. Additionally, there has been consideration that MC dysfunction might contribute to the pathogenesis of some retinal diseases, such as proliferative vitreoretinopathy, diabetic retinopathy, macular edema, retinal vein occlusion, macular telangiectasia type 2, age-related macular degeneration, retinal degeneration, hepatic and methanol-induced retinopathy, and glaucoma. This review is a summary of the functions of MCs and a discussion of the importance of these glial cells.
\end{abstract}

Keywords: Architectural and metabolic support, functions, Müller cell.

\section{Introduction}

Müller cells (MCs) (retinal gliocytes, Müller glia) are the most common of the 3 glial cells found in the human retina, followed by astroglia and microglia. Retinal gliocytes were first described by Heinrich Müller (I). The MC is the only retinal glial cell sharing a common cell line with retinal neurons. MCs have been shown to originate from neural crest cells (2).

A single progenitor cell forms both MCs and retinal neurons. The early phase of neurons born at the apical border of neuroepithelium adjacent to the pigment epithelium produces cone cells, horizontal cells, and ganglion cells, while the second phase of cells produces MCs, rod photoreceptors, bipolar cells, and amacrine cells (2-3).

MCs cover the entire thickness of the retina and have interactions with every type of neuronal cell body. MCs are aligned radially in the retina. The uppermost portion of the MCs creates the internal limiting membrane, which separates the retina from the vitreous. The cell bodies sit on the inner nuclear layer. The apical portion extends to the rear to form the outer limiting membrane and separates the inter- nal and external parts of the photoreceptors. MCs contain blood vessels in the plexiform and nerve fiber layers (Fig. I). MCs fill gaps in the retina that the neuron cells do not fill. As all glial cells do, they serve as support cells for neurons. MCs contribute to the internal blood-retinal barrier formed by endothelial cells by inducing the synthesis of tight junction and tight junction proteins (4).

MCs contribute important structural and metabolic functions to ensure the viability and stability of retinal cells. They work in a symbiotic relationship with neurons. MCs interconnect the neural elements of the retina with synapses and dendrites. MCs serve as a soft substrate for neurons to protect them in case of mechanical trauma and also for neuronal development and neuronal plasticity. Furthermore, MCs may differentiate into neural progenitors or stem cells that reproduce lost photoreceptors and neurons under pathological conditions $(5,6)$. Research continues to examine their role in neural regeneration in humans $(7,8)$. Studies in human models have shown that MCs have the potential to serve as stem cells in the adult retina and are rod pho- 


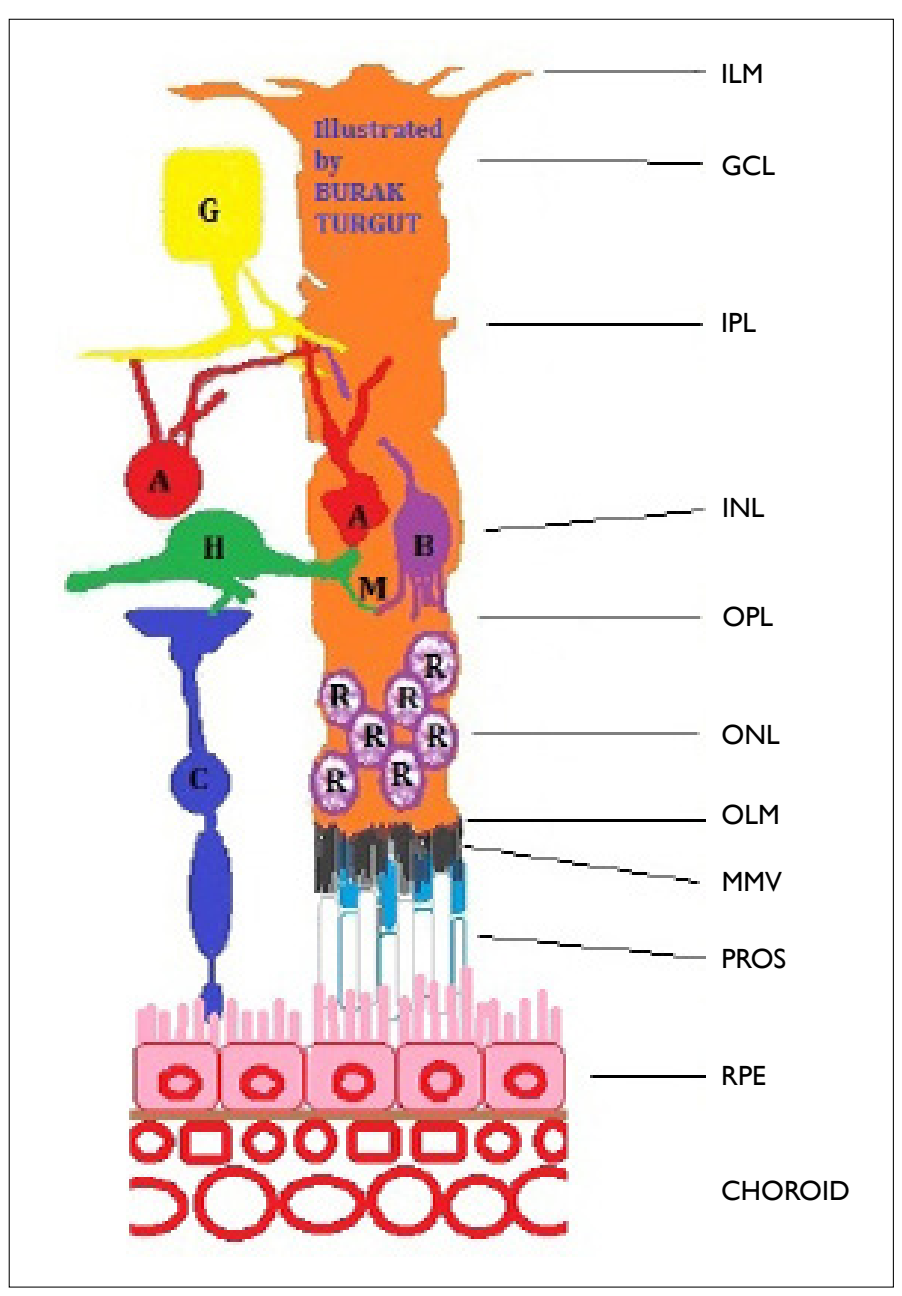

Figure I. Schematic drawing of the relationship between a Müller cell and other retinal neurons.

A: Amacrine cell; B: Bipolar cell; C: Cone cell; G: Ganglion cell; GCL: Ganglion cell layer; H: Horizontal cell; ILM: Inner limiting membrane; INL: Inner nuclear layer; IPL: Inner plexiform layer; M: Müller cell; MMV: Müller micro-villi; OLM: Outer limiting membrane; ONL: Outer nuclear layer; OPL: Outer plexiform layer; PROS: Photoreceptor outer segments; R: Rod cell; RPE: Retinal pigmented epithelium.

toreceptor progenitors. Damage to retinal cells causes MCs to undergo gliosis. It is known that the destruction of MCs can lead to the development of a macular hole or pseudohole. The result of the response depends on the damage and the organism in which damage occurs. In the zebrafish genus, MCs have been shown to differentiate into multipotent progenitor cells. The progenitor cell may be divided and differentiated into a number of retinal cell types, including photoreceptor cells that may have been damaged during injury $(9-I I)$.

The unique funnel shape of MCs, the radial alignment in the retina, and more suitable physical properties allow light to be transmitted from the vitreous to the photoreceptors behind the retina $(3,4)$. The cytoplasm of MCs contains several mitochondria that help to reduce light scattering and are enriched with long, thin filaments that form the dielectric anisotropy. The characteristics of MCs contrast with the rest of the retina, which has a surprisingly high light scattering effect. Other research has shown that MCs have acted as a funnel to provide light to rod and cone photoreceptors in the mammalian eye, similar to fiber optic plates (I2).

MCs are thought to synthesize retinoic acid from retinol and to recycle the photopigments via the transport and conversion of bleached photopigments. Additionally, they contribute to the generation of the electroretinogram (ERG) bwave, the slow P3 component of the ERG, and the scotopic threshold response $(13,14)$.

MCs have effects on voltage-gated ion channels, neurotransmitter receptors, and various carrier systems (I5). These properties allow MCs to control the activity of retinal neurons by regulating the extracellular concentration of neuroactive substances such as potassium $(\mathrm{K}+)$, gammaaminobutyric acid (GABA), and glutamate. They protect neurons from harmful changes in the ionic environment. Furthermore, they control the composition of extracellular fluid by mediating intracellular ion, water, and bicarbonate transport. In rats, aquaporin-4 in the MCs was reported to transfer water to the vitreous (14). These cells also synthesize and store glucose, and provide glucose to neighboring cells. MCs contain glycogen, mitochondria, and intermediate filaments. They are immunoreactive for vimentin, and for glial fibrillary acidic protein (GFAP), to some extent. These second filaments are normally found in the inner half and the ends of MCs. However, following trauma to the retina, in cases such as retinal detachment, both vimentin and GFAP are massively up-regulated and present throughout the cell $(17,18)$. MCs remove neural waste, such as carbon dioxide and ammonia and recycle used amino acid transmitters. It has been shown that MCs in chicken embryos were important in inducing glutamine synthetase, an actor in the regulation of glutamine and ammonia concentrations in the central nervous system (19).

MCs not only participate in extracellular homeostasis, neuronal waste removal, and transport of metabolites, but also directly contribute to the processing of information in the retina. They may produce, store, or release neuroactive substances, most likely in immediate reaction to neuronal activity or metabolic condition. Such materials may include adenosine 5'-triphosphate (ATP), glutamate, and D-serine. The protective effects of reactive MCs include the regulation of ATP-degrading ectoenzymes. This effect is achieved by increasing the extracellular presence of adenosine, a neuroprotectant, by preventing the osmotic release of ATP, which can protect retinal ganglion cells from apoptosis, and by increasing the release of antioxidants and neurotrophic factors $(4,20)$. 
Since they defend the retina against free radicals, MCs may have a significant neuroprotective effect. MCs protect neurons through the secretion of neurotrophic factors, intake and degradation of glutamate and excitotoxins, and antioxidant and glutathione secretion (17). MCs synthesize glutathione from glutamate, cysteine, and glycine. Reduced glutathione is delivered to neurons and acts as a cleanser for free radicals and reactive oxygen compounds. In the event of hypoxia or hypoglycemia, the glutathione level in MCs is dramatically reduced. A lack of glutathione due to ischemia may increase the intraretinal level of oxygen-derived free radicals. MCs obtained from older animals contained a smaller quantity of glutathione compared to the cells seen in young animals. Therefore, the decrease in the MC-mediated defense against free radicals due to age may accelerate the pathogenesis of retinopathy in elderly patients $(16,20)$.

Another means of neuroprotection is the uptake and/or detoxification of potentially harmful substances or particles by MCs. This includes phagocytosis of dead neurons or pigment epithelial cells and debris from foreign bodies, such as copper particles or latex particles. MCs are thought to remove large molecules from the extracellular matrix and possibly induce glutathione synthetase, the only enzyme present in the retina for ammonia detoxification. They can play a role in both neuronal debris phagocytosis and the release of neuroactive substances such as GABA, taurine, and dopamine. It has been demonstrated that neurotransmitters (GABA as well as acetylcholine) served as important mediators in the deterioration and preservation of a suitable retinal microenvironment in turtles $(16,17,20)$.

MCs are important for the preservation of retinal homeostasis and play a role in the regulation of the blood-retinal barrier. Thus, the blood need and angiogenesis of the retina are controlled (2I). In general, MCs increase the barrier function of the vascular endothelium through the secretion of factors such as pigment epithelium-derived factor, thrombospondin-I, neurturin, and glial cell-derived neurotrophic factor. In response to hypoxia, a high glucose level, or inflammation conditions, multiple signaling pathways are activated in MCs, followed by an increase in proangiogenic factors, such as vascular endothelial growth factor (VEGF), basic fibroblast growth factor (bFGF), matrix metalloproteinases, netrin-4, and angiopoietin-4. These changes are important features of retinal diseases, including diabetic retinopathy (DR), retinal vein occlusion, macular telangiectasia type 2 , and some forms of age-related macular degeneration (ARMD) (22-26). It will be of great interest to learn if including neurotrophins and perhaps other trophic factors with anti-VEGF drugs is beneficial to preserve neuronal viability in patients subjected to long-term anti-VEGF treatment for DR, diabetic macular edema, advanced neovascular ARMD, retinopathy of prema- turity, and other hypoxic retinal diseases (27).

Posterior vitreous separation from the retina is associated with mechanical stress in MCs, resulting in the secretion of vascular permeability factors, including bFGF. MCs are also a source of matrix metalloproteinases that break down occludin, a tight binding protein. This stimulates high glucose proteinase production. Epiretinal membranes are a prominent type of scar that connects retinal tissue with hypertrophic MC fibers. These membranes are thought to protect the retina from the effects of pathogenic factors in the vitreous. After partial separation of the vitreous from the retina, vitreous fibers adhering to MCs at the vitreoretinal attachment sites exert traction on the cells. This event activates cells and results in cellular hypertrophy and proliferation as well as vascular leakage. Mechanically stressed MCs secrete growth factors (e.g., bFGF) and ATP. The intracytoplasmic swelling of $M C$ corresponds to retinal swelling and liquefaction necrosis of MCs and leads to cystoid macular edema. MCs have been detected in epiretinal tissues in fibrovascular-contractive retinal disorders, such as proliferative vitreoretinopathy (PVR) and proliferative DR (28-34).

Primary MC failure has been proposed as the cause of different cases of retinal degeneration, including hepatic and methanol-induced retinopathy and glaucoma. Almost all pathogenic stimuli activate MCs. Reactive MCs demonstrate protective and toxic effects on photoreceptors and neurons. They contribute to oxidative stress and glutamate toxicity due to glutamate uptake and glutathione synthesis failures. Reduction of intercellular potassium and water permeability causes neuronal hyperexcitability and edema (35-38).

In a glaucomatous retina, MCs are reactivated (gliosis). Reactive MCs undergo various changes in their cellular physiology, biochemical, and morphological properties. Reactive MCs can also produce cytotoxic factors, including nitric oxide, tumor necrosis factor alpha, reactive oxygen species, and prostaglandin E2, thereby inducing apoptosis of the retinal ganglion cell and causing cell death $(25,39-43)$.

\section{Conclusion}

MCs have an important architectural and metabolic role that affects the retina. MC dysfunction may cause the development of vitreoretinal diseases, such as PVR, DR, macular edema, retinal vein occlusion, macular telangiectasia type 2 , ARMD, retinal degeneration, hepatic- and methanol-induced retinopathy, and glaucoma. Greater understanding of the functions of MCs and the results of dysfunctions will be of great importance in the development of new therapeutic approaches for some vitreoretinal diseases.

\section{Disclosures}

Peer-review: Externally peer-reviewed.

Conflict of Interest: None declared. 
Authorship Contributions: Involved in design and conduct of the study (SGK, BT); preparation and review of the study (SGK, BT); data collection (SGK, BT); and statistical analysis (SGK, BT).

\section{References}

I. Müller H. Zur Histologie der Netzhaut. [Article in Germany] Z Wissenschaft Zool I85।;3:234-7.

2. Bhattacharjee J, Sanyal S. Developmental origin and early differentiation of retinal Müller cells in mice. J Anat 1975; 120:36772.

3. Sild M, Ruthazer ES. Radial glia: progenitor, pathway, and partner. Neuroscientist 201 I; 17:288-302. [CrossRef]

4. Bernardos RL, Barthel LK, Meyers JR, Raymond PA. Late-stage neuronal progenitors in the retina are radial Müller glia that function as retinal stem cells. J Neurosci 2007;27:7028-40.

5. Goldman D. Müller glial cell reprogramming and retina regeneration. Nat Rev Neurosci 2014;15:431-42. [CrossRef]

6. Hamon A, Roger JE, Yang XJ, Perron M. Müller glial cell-dependent regeneration of the neural retina: An overview across vertebrate model systems. Dev Dyn 2016;245:727-38. [CrossRef]

7. Bhatia B, Jayaram H, Singhal S, Jones MF, Limb GA. Differences between the neurogenic and proliferative abilities of Müller glia with stem cell characteristics and the ciliary epithelium from the adult human eye. Exp Eye Res 201 I;93:852-6I. [CrossRef]

8. Cislo-Pakuluk A, Marycz K. A Promising Tool in Retina Regeneration: Current Perspectives and Challenges When Using Mesenchymal Progenitor Stem Cells in Veterinary and Human Ophthalmological Applications. Stem Cell Rev Rep 2017; I 3:598-602. [CrossRef]

9. Phillips JB, Blanco-Sanchez B, Lentz JJ, Tallafuss A, Khanobdee $\mathrm{K}$, Sampath S, et al. Harmonin (Ush Ic) is required in zebrafish Müller glial cells for photoreceptor synaptic development and function. Dis Model Mech 201 I;4:786-800. [CrossRef]

10. Fausett BV, Goldman D. A role for alphal tubulin-expressing Müller glia in regeneration of the injured zebrafish retina. J Neurosci 2006;26:6303-13. [CrossRef]

I I. Raymond PA, Barthel LK, Bernardos RL, Perkowski J. Molecular characterization of retinal stem cells and their niches in adult zebrafish. BMC Dev Biol 2006;6:36. [CrossRef]

12. Franze K, Grosche J, Skatchkov SN, Schinkinger S, Foja C, Schild $D$, et al. Muller cells are living optical fibers in the vertebrate retina. Proc Natl Acad Sci U S A 2007; 104:8287-92. [CrossRef]

13. Giannelli SG, Demontis GC, Pertile G, Rama P, Broccoli V. Adult human Müller glia cells are a highly efficient source of rod photoreceptors. Stem Cells 201 I;29:344-56. [CrossRef]

14. Reichenbach A, Faude F, Enzmann V, Bringmann A, Pannicke T, Francke $M$, et al. The Müller (glial) cell in normal and diseased retina: a case for single-cell electrophysiology. Ophthalmic Res 1997;29:326-40. [CrossRef]

I5. Jo AO, Ryskamp DA, Phuong TT, Verkman AS, Yarishkin O, MacAulay N, et al. TRPV4 and AQP4 Channels Synergistically Regulate Cell Volume and Calcium Homeostasis in Retinal Müller Glia. J Neurosci 2015;35:I3525-37. [CrossRef]
16. Bringmann A, landiev I, Pannicke T, Wurm A, Hollborn M, Wiedemann $P$, et al. Cellular signaling and factors involved in Müller cell gliosis: neuroprotective and detrimental effects. Prog Retin Eye Res 2009;28:423-5I. [CrossRef]

17. Wu K Wu KH, Madigan MC, Billson FA, Penfold PL. Differential expression of GFAP in early $v$ late AMD: a quantitative analysis. $\mathrm{Br}$ J Ophthalmol 2003;87:I I59-66. [CrossRef]

18. Bringmann A, Pannicke T, Grosche J, Francke M, Wiedemann P, Skatchkov SN, et al. Müller cells in the healthy and diseased retina. Prog Retin Eye Res 2006;25:397-424. [CrossRef]

19. Fischer AJ, Reh TA. Müller glia are a potential source of neural regeneration in the postnatal chicken retina. Nat Neurosci 200I;4:247-52. [CrossRef]

20. Li Q, Puro DG. Diabetes-induced dysfunction of the glutamate transporter in retinal Müller cells. Invest Ophthalmol Vis Sci 2002;43:3109-16.

2I. Li X, Liu J, Hoh J, Liu J. Müller cells in pathological retinal angiogenesis. Transl Res 2019;207:96-106. [CrossRef]

22. Browning DJ, Stewart MW, Lee C. Diabetic macular edema: Evidence-based management. Indian J Ophthalmol 2018;66:173650. [CrossRef]

23. de Hoz R, Rojas B, Ramírez Al, Salazar JJ, Gallego BI, Triviño $A$, et al. Retinal Macroglial Responses in Health and Disease. Biomed Res Int 2016;2016:295472I. [CrossRef]

24. Tretiach M, Madigan MC, Wen L, Gillies MC. Effect of Müller cell co-culture on in vitro permeability of bovine retinal vascular endothelium in normoxic and hypoxic conditions. Neurosci Lett 2005;378:160-5. [CrossRef]

25. Powner MB, Gillies MC, Tretiach M, Scott A, Guymer RH, Hageman GS, et al. Perifoveal müller cell depletion in a case of macular telangiectasia type 2. Ophthalmology 2010; I 17:240716. [CrossRef]

26. Coughlin BA, Feenstra DJ, Mohr S. Müller cells and diabetic retinopathy. Vision Res 2017;139:93-100. [CrossRef]

27. Le YZ. VEGF production and signaling in Müller glia are critical to modulating vascular function and neuronal integrity in diabetic retinopathy and hypoxic retinal vascular diseases. Vision Res 2017;139:108-14. [CrossRef]

28. Wen R, Song Y, Cheng T, Matthes MT, Yasumura D, LaVail MM, et al. Injury-induced upregulation of bFGF and CNTF mRNAS in the rat retina. J Neurosci 1995; I5:7377-85. [CrossRef]

29. Harada T, Harada C, Nakayama N, Okuyama S, Yoshida K, Kohsaka S, et al. Modification of glial-neuronal cell interactions prevents photoreceptor apoptosis during light-induced retinal degeneration. Neuron 2000;26:533-4I. [CrossRef]

30. Hauck SM, KinkI N, Deeg CA, Swiatek-de Lange M, Schöffmann S, Ueffing M. GDNF family ligands trigger indirect neuroprotective signaling in retinal glial cells. Mol Cell Biol 2006;26:274657. [CrossRef]

31. Giebel SJ, Menicucci G, McGuire PG, Das A. Matrix metalloproteinases in early diabetic retinopathy and their role in alteration of the blood-retinal barrier. Lab Invest 2005;85:597-607.

32. Tso MO. Pathology of cystoid macular edema. Ophthalmology 
1982;89:902-15. [CrossRef]

33. Ersanlı D. Causes of macular edema. Ret-Vit special volume 2015;23:172-7.

34. Guidry C. The role of Müller cells in fibrocontractive retinal disorders. Prog Retin Eye Res. 2005;24:75-86. [CrossRef]

35. Albrecht J, Gadamski R, Kuhrt H, Walski M, Reichenbach A. Retinal gliopathy accompanying thioacetamide-induced liver insufficiency: light and electron microscopic observations. Acta Neuropathol 1998;96:57-66. [CrossRef]

36. Lam TT, Kwong JM, Tso MO. Early glial responses after acute elevated intraocular pressure in rats. Invest Ophthalmol Vis Sci 2003;44:638-45. [CrossRef]

37. Tezel G, Chauhan BC, LeBlanc RP, Wax MB. Immunohistochemical assessment of the glial mitogen-activated protein kinase activation in glaucoma. Invest Ophthalmol Vis Sci 2003;44:302533. [CrossRef]

38. Gungor K. Gene Therapy in Glaucoma. Turkiye Klinikleri J
Ophthalmol-Special Topics 2012;5:83-7.

39. Liu ST, Zhong SM, Li XY, Gao F, Li F, Zhang ML, et al. EphrinB/ EphB forward signaling in Müller cells causes apoptosis of retinal ganglion cells by increasing tumor necrosis factor alpha production in rat experimental glaucomatous model. Acta Neuropathol Commun 2018;6:III. [CrossRef]

40. Behzadian MA, Wang XL, Windsor LJ, Ghaly N, Caldwell RB. TGF-beta increases retinal endothelial cell permeability by increasing MMP-9: possible role of glial cells in endothelial barrier function. Invest Ophthalmol Vis Sci 200I;42:853-9.

4l. Fletcher EL, Phipps JA, Wilkinson-Berka JL. Dysfunction of retinal neurons and glia during diabetes. Clin Exp Optom 2005;88: 1 32-45. [CrossRef]

42. Gao F, Ji M, Wu JH, Wang ZF. Roles of retinal Müller cells in health and glaucoma. [Article in Chinese] Sheng Li Xue Bao 2013;65:654-63.

43. Seitz R, Ohlmann A, Tamm ER. The role of Müller glia and microglia in glaucoma. Cell Tissue Res 2013;353:339-45. [CrossRef] 